Research Article

\title{
Epidemiological Investigation of Acute Gastroenteritis in a Residential Campus Area of Delhi, India
}

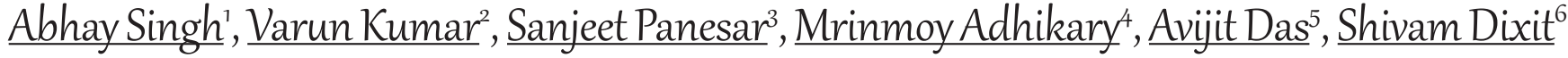 \\ ${ }^{1}$ Lecturer, Department of Community, Medicine, Government Medical College, Banda, U.P. \\ ${ }^{2}$ Assistant Professor, Department of Community Medicine, Government Medical College and ESI Hospital, Coimbatore, Tamil \\ Nadu. \\ ${ }^{3}$ Assistant Professor, Department of Community Medicine, Government Medical College, ABVIMS and Dr. RML Hospital, New \\ Delhi. \\ ${ }^{4}$ Assistant Professor, Department of Community Medicine, Murshidabad Medical College and Hospital, West Bengal. \\ ${ }^{5}$ Demonstrator, Department of Community Medicine, College of Medicine and Sagure, Kamarhati, Kolkata. \\ ${ }^{6}$ Assistant Professor (Statistics \& Demography), Department of Community Medicine, MGM Medical College, Indore. \\ DOI: https://doi.org/10.24321/2455.7048.201910
}

\section{I $\quad \mathbf{N} \quad \mathbf{F} \quad \mathbf{O}$}

\section{Corresponding Author:}

Abhay Singh, Department of Community, Medicine, Government Medical College, Banda, U.P.

E-mail Id:

singdr.abhay@yahoo.com

Orcid Id:

https://orcid.org/0000-0002-4148-5783

How to cite this article:

Singh A, Kumar V, Panesar S et al. Epidemiological Investigation of Acute Gastroenteritis in a Residential Campus Area of Delhi, India. Epidem Int 2019; 4(2): 34-38.

Date of Submission: 2019-07-25

Date of Acceptance: 2019-10-14

\section{$\begin{array}{llllllll}\mathbf{A} & \mathbf{B} & \mathbf{S} & \mathbf{T} & \mathbf{R} & \mathbf{A} & \mathbf{C} & \mathbf{T}\end{array}$}

Background: This report is about the investigation of an outbreak of acute gastroenteritis that claimed two human lives and left 180 people affected within one week of its outbreak in a residential campus area in Delhi, India in the month of June 2013. The study was conducted to find out the causes of acute gastroenteritis outbreak and to suggest preventive and control measures.

Methods: A cross sectional study was designed and a pre-tested predesigned epidemiological case sheet was used and a total of 180 cases of acute gastroenteritis were interviewed. Contribution by ecological factors was also assessed. Stool and water samples were also collected.

Results: Out of 14000 inhabitants, 180 people suffered from similar complaints of acute gastroenteritis. Males and females were almost equally affected although people in the age group 15 - 44 completed years, 88 (48.8\%) and those living in type I quarters, 108 (60\%) were affected most. Epidemic curve with single peak was obtained. Environmental surveillance revealed breakage of drinking water pipelines and mixing of drinking water with sewage water near type I quarters. Out of 14 stool samples collected, one was positive for Vibrio cholerae (ogawa serotype).

Conclusion: The present study reflected the possible contamination drinking water with sewage water in outbreak of gastroenteritis. By employing simple epidemiological field investigation, the outbreak was brought under control.

Keywords: Outbreak Investigation, Acute Gastroenteritis, Sewage Water 


\section{Introduction}

World Health Organization (WHO) has defined outbreak as the occurrence of cases of an illness which may be a specific heath related behavior or other event, clearly in excess of normal expectancy in a community in a specific time period. A single case of a communicable disease long absent from a population or caused by an agent not previously recognized in that community or area, or the emergence of a previously unknown disease, may also constitute an outbreak. An outbreak may occur in a restricted geographical area, or may extend over several countries. It may last for a few days or weeks, or for several years. All efforts should be made to investigate such outbreaks at the earliest to prevent further spread. ${ }^{1}$

Contaminated food and water sources are the main causes of acute gastroenteritis or diarrheal disease which is a leading cause of child mortality and morbidity in the world. Diarrhea is a symptom of infections caused by a host of bacterial, viral and parasitic organisms, most of which are spread by feces-contaminated water. Infection is more common when there is a shortage of adequate sanitation and hygiene and safe water for drinking, cooking and cleaning. Rotavirus and Escherichia coli are the two most common etiological agents of diarrhea in developing countries. Worldwide, 780 million individuals lack access to improved drinking-water and 2.5 billion lack improved sanitation. Diarrhea due to infection is widespread throughout developing countries. ${ }^{2}$

The Millennium Development Goal (MDG) target for providing safe water supply for the year 2010 has been reached. Over 2 billion people gained access to improved water sources increasing from 76\% in 1990 to $89 \%$ in 2010, and half of them belonged to India and China. But there are huge disparities with access to improved water supply in Sub-Saharan Africa only at $61 \% .^{3}$ Hence the outbreaks of water borne infections are more in developing countries.

It is estimated that, on average, each child under 5 years of age in a developing country suffers from three episodes of diarrhea per year, with little change over the years. ${ }^{4}$ Worldwide around 1.1 billion people lack access to improved water sources and 2.4 billion have no basic sanitation. Diarrhea due to infection is widespread throughout the developing world. In Southeast Asia and Africa, diarrhea is responsible for as much as $8.5 \%$ and $7.7 \%$ of all deaths respectively. ${ }^{5}$

Resourcing of the water, sanitation and hygiene sector is relatively low priority compared to other sectors. In many countries, policies and programs underemphasize adequate financing and human resource development to sustain the existing infrastructure and to expand access to sanitation, drinking water and hygiene services. Because of the presence of many favorable factors, the outbreak of acute gastroenteritis in a developing country like India is not uncommon. ${ }^{6}$

This report is about the investigation of an outbreak of acute gastroenteritis that claimed two human lives and left 180 people affected within one week of its outbreak in a residential campus area in Delhi, India in the month of June 2013. The study was conducted to find out the causes of acute gastroenteritis outbreak and to suggest preventive and control measures.

\section{Materials and Methods}

On $26^{\text {th }}$ June 2013 , two cases of acute gastroenteritis were admitted in the departments of Medicine and Pediatrics in Vardhman Mahavir Medical College (VMMC) and Safdarjung Hospital, New Delhi from National Council for Educational Research and Training (NCERT) residential campus. On $27^{\text {th }}$ June 2013, a rapid response team containing public health specialist, general physician, pediatrician and microbiologist was created.

\section{Study Area}

National Council for Educational Research and Training (NCERT) campus is located in the Hauz Khas block of South district of Delhi containing a population of 14,000 . The residential area is divided into five different areas as type I, II, III, IV and V. Employees working in NCERT were allotted houses according to their grades, with lower grade personnel getting type I. As the grades increase, they were allotted in increasingly higher types and employees with the highest grade were allotted type $\mathrm{V}$.

\section{Case Definition}

A case of acute gastroenteritis was defined as having three or more episodes of having watery diarrhea within 24 hour period with either abdominal cramps or fever of $\geq$ $100 \mathrm{~F}$ in the preceding two weeks among the residents of NCERT campus.

\section{Data Collection}

Data collection was done during $27^{\text {th }}$ and $28^{\text {th }}$ June 2013. The team members had with them a structured pre-tested epidemiological case sheet. Clinical history of loose motions during the previous week was recorded along with data pertaining to age, sex, occupation, source of water supply, places visited, eating habits, and disposal of excreta and solid wastes. Contribution by ecological factors was also assessed. The vials for stool sample distributed to all cases. But only 14 stool samples were received. Water samples were also collected from the households where cases had occurred and also from 12 other sites in the study area and all specimens were sent to a tertiary care hospital of Delhi (table 3).

\section{Ethics Statement}

Centers for Disease Control and Prevention determined that 
these outbreak investigations do not meet the definition of research as provided by 45 CFR4 6.102 (d) and therefore Institutional Review Board (IRB) review was not required. The basis for this determination was that the primary purpose of this activity was to identify, characterize, and control disease in response to an immediate public health threat. All participants were explained the purpose of the investigation and participation was voluntary.

\section{Statistical Analysis}

Data were entered and analyzed using SPSS ver.21.

\section{Result}

The first case of the suspected outbreak of acute gastroenteritis was reported on $18^{\text {th }}$ June 2013 in the NCERT campus, Delhi. A total of 180 cases were identified. Although cases occurred in Type I, II, III, IV and V quarters, majority of the cases (60\%) were in Type I quarters. Two persons who have died of cholera were also from Type I quarters (one of which is female child of 5 years of age and another was a male aged 48 years).

Of the total cases, 101(56.1\%) were males and 79 (43.9\%) were females. The proportion of cases $<4$ years of age was $6.7 \%, 13.9 \%$ of cases belonged to age group between 5 \& 14 years. Majority (79.4\%) of cases were aged 15 years or more. Majority $(86.7 \%)$ of cases had occurred in Type I \& II Flats, followed by $8.9 \%$ in Type III, $2.2 \%$ in Type IV and $2.2 \%$ in Type V Quarters.
Table I.Distribution at Cases according to sociodemographic profile

\begin{tabular}{|c|c|c|c|c|}
\hline S. No. & \multicolumn{2}{|c|}{ Socio demographic variables } & Cases & $\%$ \\
\hline \multirow{4}{*}{1.} & \multirow{4}{*}{$\begin{array}{c}\text { Age in completed } \\
\text { yearsz }\end{array}$} & $<4$ & 12 & 6.7 \\
\hline & & $5-14$ & 25 & 13.9 \\
\hline & & $15-44$ & 88 & 48.8 \\
\hline & & $>45$ & 55 & 38.6 \\
\hline \multirow{2}{*}{2.} & \multirow{2}{*}{ Sex } & Male & 101 & 56.1 \\
\hline & & Female & 79 & 43.9 \\
\hline \multirow{5}{*}{3.} & \multirow{5}{*}{ Type of houses } & 1 & 108 & 60.0 \\
\hline & & 2 & 48 & 26.7 \\
\hline & & 3 & 16 & 8.9 \\
\hline & & 4 & 4 & 2.2 \\
\hline & & 5 & 4 & 2.2 \\
\hline
\end{tabular}

\section{Epidemic Curve}

Epidemic curve suggests that single source of pathogen resulted in exposure of persons at one point in time; so it was a point source epidemic. Further analysis of the epidemic curve suggests that the median date of onset of illness: $25^{\text {th }}$ June 2013 and the probable time of exposure as $15^{\text {th }}$ June 2013.

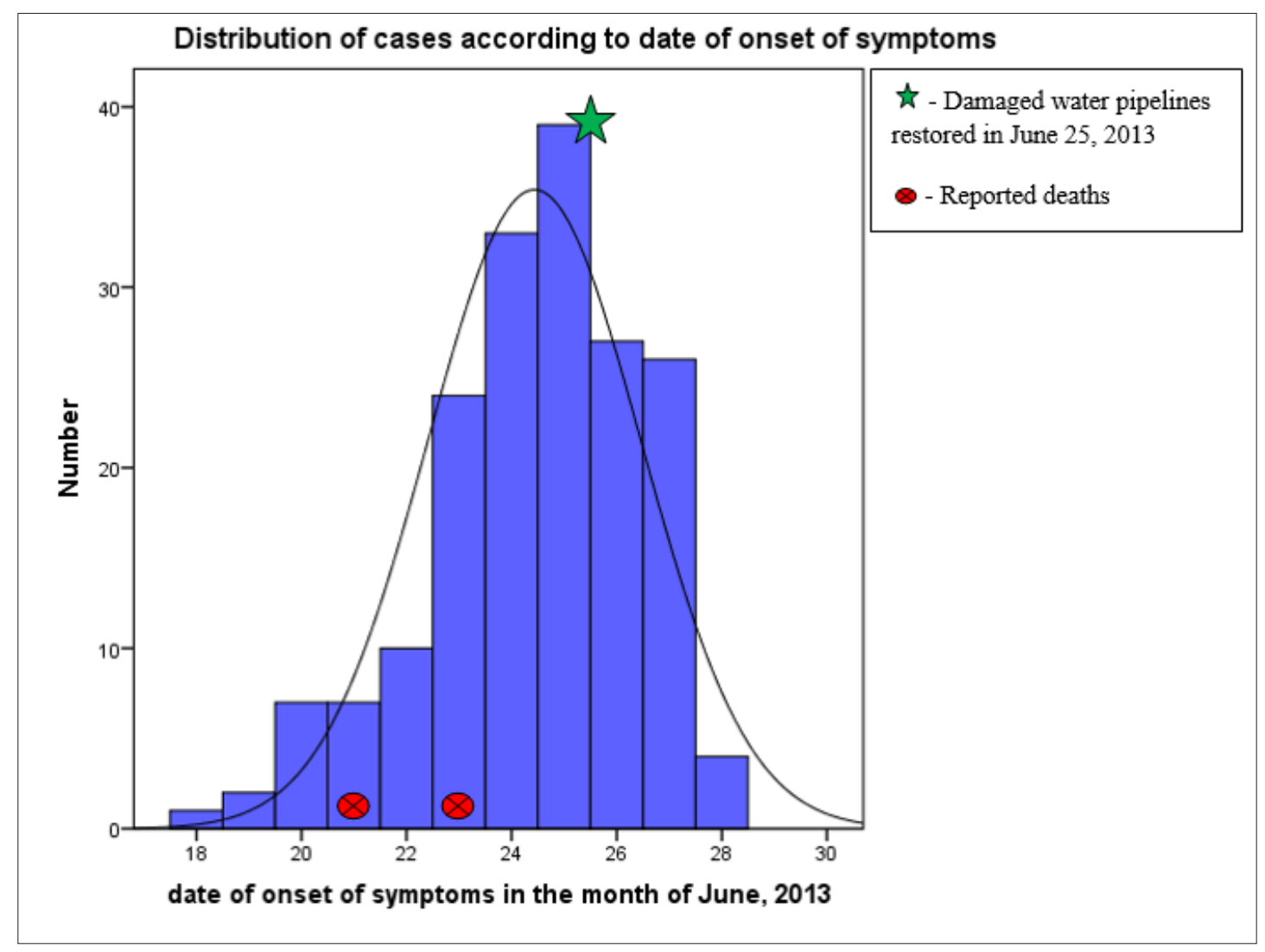




\section{Environmental Assessment}

It was found that the residual chlorine level in the worst affected area was low as compared to the areas which were least affected. Furthermore, residual chlorine level of the water supplied by Delhi Jal Board (DJB) was found to be satisfactory.

\section{Spot Map}

Clustering of the cases near Type I quarters suggests that the outbreak probably occurred because of the consumption of the contaminated water coming through water pipelines. This is further supported by the 'Environmental Assessment' that the contamination of the drinking water with sewage water had taken place in Type I Block having quarters nos. from 17-48.

\section{Microbiological examination of water and stool samples}

Of the 12 water samples taken on $27^{\text {th }}$ and $28^{\text {th }}$ June 2013
6 were found to be unfit for consumption (Table 3). But all the water samples taken on $4^{\text {th }}$ July 2013, after Central Public Works Department (CPWD) had taken remedial measures, all sites were found to be fit for consumption. All 14 stool samples were negative for any ova or cyst. No pathogenic bacteria were isolated except in one sample which was positive for Vibrio cholerae (ogawa serotype).

\section{Control Measures Taken}

The broken pipe line in Type-I quarters numbers 17-48 was replaced by CPWD on $25^{\text {th }} \& 26^{\text {th }}$ June 2013 . Chlorination at various places was found insufficient; it was also done properly by CPWD from $2^{\text {nd }}$ July 2013 onwards. Health talk regarding prevention and control of acute gastroenteritis was delivered on $2^{\text {nd }}$ July 2013. Furthermore, patients and their families were advised to observe hygiene practices, residents and experts, during house to house visits and at satellite clinic. CPWD officials were demonstrated about how to use Horrock's apparatus and the Chlorimeter.

Table 2.Residual Chlorine Level and Chlorine Demand at various sites in the study area

\begin{tabular}{|c|c|c|c|}
\hline S. No. & Name of the Site & $\begin{array}{c}\text { Horrock's Apparatus (for } \\
\text { Chlorine Demand) }\end{array}$ & $\begin{array}{c}\text { Chlorimeter } \\
\text { (Residual Chlorine in ppm*) }\end{array}$ \\
\hline 1. & Pump House & $2 \mathrm{gms} / 500$ Ltr. & 0.8 \\
\hline 2. & Delhi Jal Board Tanker & $4 \mathrm{gms} / 500$ Ltr. & 0.8 \\
\hline 3. & Type II/ 33 Quarter & $2 \mathrm{gms} / 500$ Ltr. & 1.0 \\
\hline 4. & Type V Quarter & $2 \mathrm{gms} / 500$ Ltr. & 1.0 \\
\hline 5. & Type I/ 44 Quarter & $4 \mathrm{gms} / 500$ Ltr. & 0.2 \\
\hline 6. & Tank A (Type I/ 17-48 Quarter) & $2 \mathrm{gms} / 500$ Ltr. & 0.2 \\
\hline 7. & Tank B (Behind Temple) & $2 \mathrm{gms} / 500$ Ltr. & 0.2 \\
\hline
\end{tabular}

Table 3.Bacteriological results of water samples taken from various sites in study area

\begin{tabular}{|c|c|c|c|c|c|}
\hline \multirow{2}{*}{ S. No. } & \multirow{2}{*}{ Name of the site } & \multicolumn{2}{|c|}{ Before remedial measures } & \multicolumn{2}{c|}{ After remedial measures } \\
\cline { 3 - 6 } & \multicolumn{2}{|c|}{ PCC } & \multicolumn{2}{|c|}{ PCC* } \\
\hline 1. & Library & $1-3$ & Fit for consumption & - & - \\
\hline 2. & Publication house & $4-10$ & Unfit for consumption & 0 & Fit for consumption \\
\hline 3. & Science block & $>10$ & Unfit for consumption & 0 & Fit for consumption \\
\hline 4. & Zakir Hussain block I & $1-3$ & Fit for consumption & - & - \\
\hline 5. & Zakir Hussain block II & $4-10$ & Unfit for consumption & 0 & Fit for consumption \\
\hline 6. & Type I quarters & $>10$ & Unfit for consumption & 0 & Fit for consumption \\
\hline 7. & Dhobi ghat pump house & $4-10$ & Unfit for consumption & 0 & Fit for consumption \\
\hline 8. & Main pump house & $1-3$ & Fit for consumption & - & - \\
\hline 9. & Type II quarters & $1-3$ & Fit for consumption & - & - \\
\hline 10. & Tank A (for type III, IV \& V) & 0 & Fit for consumption & - & - \\
\hline 11 & Tank B (for type I \& II) & $>10$ & Unfit for consumption & 0 & Fit for consumption \\
\hline 12 & Delhi Jal Board tanker & 0 & Fit for consumption & - & \\
\hline
\end{tabular}

*presumptive coliform count 


\section{Discussion}

The bacteriological examination of stool samples revealed V. cholerae O1, biotype El Tor, and serotype Ogawa as the causative organism. This was similar to other similar studies on acute gastroenteritis outbreak done in India. ${ }^{7,8}$ Males were affected more (56.1\%) than females and the most active age group belonging to $15-45$ years were affected more (48.8\%). This can be compared to a study done by Singh et al. ${ }^{9}$ More cases were observed in type I quarters $(60 \%)$. Two persons who have died of cholera were also from Type I quarters. The outbreak was found to be point source epidemic with a single peak.

Our environmental surveillance led us to the identification of factors which contributed to the outbreak of gastroenteritis. They were mixing of the drinking water with the sewage because of broken pipe lines in Type-I quarters nos. 1748 and contamination of partially covered and broken plastic underground water tanks near Type I Quarters. Microbiological investigations of water samples in the affected areas revealed high coliform counts.

World Health Organization (WHO) has introduced several household water interventions (HWST) including solar disinfection, bleach addition, boiling and use of low cost ceramic filters. This program will not only benefit poor communities at individual level but will also lead to a benefit of up to US\$60 for every US\$1 invested. ${ }^{10}$

No follow up of cases could be considered as the limitation of this study.

\section{Conclusion}

In the present study, it was found that mixing of the drinking water with the sewage because of broken pipe lines in Type I quarters numbers 17-48 and contamination of partially covered and broken plastic underground water tanks near Type I quarters led to the occurrence of outbreak. By employing simple epidemiological field investigation, the outbreak was brought under control.

\section{Recommendation}

A proper surveillance system for early identification of cases along with continuing health education will help in initiating and implementing prompt control measures. Greater political and financial commitment is needed to control these outbreaks.

\section{Conflict of Interest: None}

\section{References}

1. http://www.who.int/topics/disease_outbreaks/en/. Last accessed on August 7, 2013.

2. http://www.who.int/mediacentre/factsheets/fs330/ en/index.html. Last accessed on August 7, 2013.

3. http://www.wssinfo.org/fileadmin/user_upload/
resources/JMP-report-2012-en.pdf. Last accessed on August 7, 2013.

4. Kosek M, Bern C, Guerrant RL. The global burden of diarrheal disease, as estimated from studies published between 1992 and 2000. Bull World Health Organ. 2003; 81(3): 197-204.

5. http://www.who.int/water_sanitation_health/ diseases/diarrhoea/en/index.html. Last accessed on August 7, 2013.

6. http://www.unwater.org/downloads/UN-Water_ GLAAS_2012_Report.pdf. Last accessed on August 7, 2013.

7. Radhakutty G, Sircar BK, Mondal SK et al. Department of Microbiology, T.D. Medical College, Alleppey Investigation of cholera outbreak in Alleppey and Palghat district, South India. Indian J Med Res 1997; 106: 455-457.

8. Ghosh S, Sircar BL. Investigation of an outbreak of acute diarrhoeal disease in Malda district of West Bengal. National Institute of Cholera and Enteric disease (NICED), Kolkata Annual Report. 2003-2004.

9. Singh MM, Gupta SS, Thakur JS et al. Cholera in a periurban slum colony near Chandigarh. Bull PGI 1998; 32: 59-62.

10. World Health Organization: The International Network to Promote Household Water. Combating Waterborne Disease at the Household Level. 2007 [http://www.who. int/water_sanitation_health/publications/combating_ diseasepart1lowres.pdf]. Last accessed on August 7, 2013. 